\title{
Writing Across the Curriculum: Where Does Horticultural Science Fit In?
}

\author{
Karina Zambreno ${ }^{1}$, \\ Emily Hoover ${ }^{2}$, \\ Neil Anderson ${ }^{3}$, and \\ Jeffrey H. Gillman ${ }^{3}$
}

ADDITIONAL INDEX WORDS. informal writing, writing intensive, curriculum revision

SUMMARY. In Fall 1999, the University of Minnesota implemented a writingintensive (WI) requirement for undergraduates. As part of the requirement, students must take one upper-division WI course in their major. As of Spring 2002, the environmental horticulture major through the Department of Horticultural Science had only one WI course in its entire curriculum. Teaching faculty were interviewed and syllabi were reviewed to gather information on what types of writing are currently being assigned and to discuss where more WI courses should be placed in the environmental horticulture curriculum in the future. These surveys and interviews revealed that the majority of classes require formal writing and that the majority of the faculty review or are willing to review a draft of an assignment, two key components of the WI requirement. Informal writing assignments are less common, indicating a deficient area of the curriculum. With slight modifications, many classes in the environmental horticulture curriculum can meet the requirements to become designated as WI. Faculty agreed that WI courses should be placed in upper-level, smaller classes that place less emphasis on production techniques or plant identification.

${ }^{1}$ Graduate Research Assistant, currently Admissions Advising Counselor, Department of Horticultural Science, University of Minnesota, St. Paul, MN 55108.

${ }^{2}$ Professor, Department of Horticultural Science, University of Minnesota, St. Paul, MN 55108. To whom reprint requests should be addressed; e-mail: hoove001@umn.edu

${ }^{3}$ Assistant Professor, Department of Horticultural Science, University of Minnesota, St. Paul, MN 55108

This research has been supported by a grant from the Center for Interdisciplinary Studies of Writing at the University of Minnesota and in part by the Minnesota Agricultural Experiment Station. 
W riting across the curriculum has been implemented in universities and colleges in an effort to improve writing skills and encourage more thoughtful exploration of course content (Herrington, 1981). In practice, writing across the curriculum means that writing-intensive (WI) classes are offered in all departments and not limited to composition and rhetoric classes. Classes designated WI must integrate writing into the course objectives so that course content is learned, in part, through the process of writing (Herrington, 1981).

The University of Minnesota (UMN) implemented a WI requirement for undergraduates entering after Fall 1999 in order to help students develop and enhance critical thinking and written communication skills. Specific goals of the WI program are to teach students to write for a variety of audiences, learn different kinds of writing styles, and prepare students to communicate effectively in their field of study and future careers (Center for Interdisciplinary Studies of Writing, 2000).

In order for a class to be designated as WI, faculty at UMN submit a proposal along with a course syllabus that clearly indicates how writing serves the goals of the course. The main requirement is 10 to 15 pages of formal writing assignments with at least one stage of an assignment involving a critical review of a draft by the professor or a teaching assistant (Center for Interdisciplinary Studies of Writing, 2000). Without an opportunity for revision, instructor comments have little effect on improving subsequent papers (University Writing Program at Virginia Tech, 1998). Allowing for revision continues the writing process, permitting students to learn from their mistakes (Dohrer, 1991). Including peer reviews in the process has added benefits. Students feel empowered by becoming part of the review process and believe giving/receiving comments from peers enables them to become better writers (Koprowski, 1997). In addition, Koprowski (1997) found that peer reviews resulted in significantly improved papers when compared to revisions receiving critique from the instructor alone.

Faculty teaching WI courses at UMN are also advised to incorporate informal writing assignments throughout the semester that are reviewed but not graded by the instructor. These may include journal entries and brief responses to workbook questions or field trips. Informal writing gives students the opportunity to write out their thoughts on a particular subject without worrying about formatting (Madigan, 1987). If informal writing is used to explore a certain topic, there is also the possibility for early intervention by the instructor if a concept is not being understood (Madigan, 1987).

To fulfill the WI requirement at UMN, undergraduate students are required to take four WI courses, with at least one being an upper-division course in their major (Center for Interdisciplinary Studies of Writing, 2000). This particular requirement is designed to meet the goal of teaching students to communicate in their fields of study. For example, students studying science are often placed in courses where the focus lies more on learning content than learning writing skills for the discipline (Krest and Carle, 1999). Furthermore, it is difficult, if not impossible, for English and rhetoric departments to teach all of the different thought processes and styles used to write in the wide range of disciplines found at a university (Madigan, 1987). By integrating writing into science classes, the specific skills required to write in that discipline can be taught by a professional in the field and done in stages as writing assignments become more complex (Krest and Carle, 1999).

The Department of Horticultural Science at UMN offers an environmental horticulture major for undergraduates. Within the department, students take professional requirement courses and a series of courses based on their area of emphasis (Table 1). As of the Fall 2002 semester there was only one WI course in the environmental

Table 1. Required classes and number of credits for environmental horticulture majors offered through the Department of Horticultural Science at the University of Minnesota. All students must take the Professional Requirements and choose one area of emphasis for the remaining credits. The one writing-intensive class in the curriculum is marked with an asterisk $\left({ }^{*}\right)$.

\author{
Professional Requirements \\ Hort $1001 \quad$ Plant Propagation (4) \\ Hort 1011 Herbaceous Landscape Plants (4) \\ Hort 1012 Woody Landscape Plants (4) \\ Hort 3002 Greenhouse Management (3) \\ Hort 3005 Environmental Effects on Horticultural Crops (2) \\ Hort 4096 Professional Experience Program (3) \\ Hort $4401 \quad$ Plant Genetics and Breeding (4) \\ Areas of Emphasis: \\ Landscape Design, Implementation and Management \\ Hort $4021 \quad$ Landscape Design, Implementation and Management I (4) \\ Hort 5021 Landscape Design, Implementation and Management II (4) \\ Hort 5024 Landscape Development (1) \\ Hort 4061 Turf and Landscape Management (4) \\ Two additional elective courses from a list
}

Nursery Production and Garden Center Management

Hort $4041 \quad$ Nursery Production and Management I (4)*

Hort 5041 Nursery Production and Management II (3)

Hort $5042 \quad$ Nursery Operations (1)

Two additional elective courses from a list

Greenhouse Production and Retail Floriculture

Hort 4051 Potted Plant Production (4)

Hort $5051 \quad$ Bedding Plant Production (4)

Hort 5052 Cut Flower Production (4)

Two additional elective courses from a list

Turfgrass Management

Hort $4021 \quad$ Landscape Design, Implementation and Management I (4)

Hort 4061 Turfgrass and Landscape Management (4)

Hort 5061 Turfgrass Science (3)

Two additional elective courses from a list 
horticulture curriculum, Hort 4041, a nursery production and garden center management course. Offering only one WI course makes it impossible for students in other areas of emphasis to easily fulfill the WI requirement. There is a strong need, therefore, for more WI courses in the curriculum. A grant from the Center for Interdisciplinary Studies of Writing at the University of Minnesota enabled exploration of the current state of writing in our department and curriculum. The purpose of this study was to characterize current writing assignments and to collect information for further discussions on the role of WI courses within the environmental horticulture curriculum.

\section{Materials and methods}

Interviews were conducted with 13 of the 14 current teaching faculty in the Department of Horticultural Science teaching a total of 21 classes in the environmental horticulture curriculum. Prior to each interview, copies of syllabi for all classes taught by the faculty member were collected to calculate the percentage of course grades based on writing. During the interview, writing assignments for each class were characterized by type and length. Faculty were also asked about the procedure they currently use for responding to preliminary drafts.

The last part of the interview consisted of gathering opinions on how writing is currently used in the environmental horticulture undergraduate curriculum. Faculty were asked what type of courses within the curriculum should be WI. They were also asked if they thought there was sufficient writing in the curriculum. They could answer "yes," "no," or "I don't know." When the answer was "no" or "I don't know," additional comments about perceived weaknesses and recommendations for ways in which writing assignments should change were also recorded. Other topics discussed included the quality of students' writing, usefulness of critical reviews of drafts, and concerns about grading writing assignments.

After all of the interviews had been completed, the information gathered on the writing assignments was categorized into discrete units of formal and informal writing. Formal types of writing were separated into primary and secondary research, while informal writing was left as its own category and not subdivided. Primary research was defined as assignments based on original data gathered by the student and presented in the form of a lab report or design project. Secondary research was defined as that gathered from outside sources, such as journal articles, trade publications, books, and the internet, and was presented in forms such as literature reviews or informative reports on a specific topic. To determine how these types of writing assignments were utilized, the number of the types of assignments used in each class was determined.

Results from the questions regarding the presence of sufficient writing in the curriculum were summarized as percentages of the total number of faculty interviewed (Table 2, question $1)$. Results from questions regarding the different types of writing assignments used in each class were treated in two ways. First, the number of classes assigning a particular type of assignment was calculated (Table 2 , question 2 ). Second, the classes were further characterized by how many and what types of writing they assigned (Table 2 , question 3 ). Results from questions about the percentage of course grades based on writing were divided into four categories $(<25 \%, 26 \%$ to $50 \%$, $51 \%$ to $75 \%,>75 \%)$. The percentage of classes falling in each category was then calculated (Table 2, question 4).

\section{Results}

There was a fairly even split when faculty were asked if there was sufficient writing in the current curriculum (Table 2 , question 1 ). Four of the faculty felt there was not enough, while five felt there was already enough writing. The remaining four either did not know how writing was being used across the curriculum or if the amount of writing was sufficient. However, there was consensus that at least one WI course should be in each emphasis within the curriculum at the upper-division level (Table 1).

When characterizing how the primary research, secondary research, and informal writing were utilized (presence or absence of a particular type of writing in a class), the greatest numbers of classes assigned a secondary research project and the majority of classes assigned a primary research project (Table 2, question 2). Less than one-third of the classes utilized informal writing. When looking at how the types of writing were combined within a class, almost half used only primary or secondary research for all writing assignments (Table 2, question 3). None of the classes used only informal writing. About one-quarter of the classes integrated all three types of writing into their assignments and one class used secondary research and informal writing. Half of the classes required formal writing assignments (primary or secondary research) that totaled at least 10 pages and half of the instructors reviewed a rough draft of part or all of an assignment (data not shown).

Almost half of the classes in the curriculum had between $26 \%$ and $50 \%$ of their grade based on writing (Table 2 , question 4). Seven of the 21 classes based the majority of student grades on writing.

Table 2. Survey results of 13 Department of Horticultural Science teaching faculty on the presence of writing in the environmental horticulture, the types of writing assignments, and percentage of grade based on writing in the 21 classes.

1. Is there sufficient writing in the current curriculum $(n=13)$ ?

$\begin{array}{ll}\text { Yes } & 31 \% \\ \text { No } & 38 \% \\ \text { Don't know } & 31 \%\end{array}$

2. What percentage of the classes assigns each of the three writing types $(\mathrm{n}=21)$ ?

$\begin{array}{ll}\text { Primary research } & 57 \% \\ \text { Secondary research } & 71 \% \\ \text { Informal writing } & 29 \%\end{array}$

3. How do the classes utilize the three writing types $(\mathrm{n}=21)$ ?

No writing assignments $\quad 9 \%$

Primary research only 19\%

Secondary research only $\quad 29 \%$

Informal writing only

Primary and secondary research

Secondary research and informal writing

Primary research and informal writing

Primary, secondary, and informal writing

4. What percentage of the grade is based on writing in the classes $(n=21)$ ?

$<25 \%$

$26 \%$ to $50 \%$

$48 \%$

$51 \%$ to $75 \%$

$24 \%$

$>75 \%$ 


\section{Discussion}

Results of these interviews indicate that, although only one class in the environmental horticulture curriculum is classified as WI, many of the classes already meet the requirements to become a WI course or could meet the criteria with slight modifications of writing assignments and/or syllabi. The majority of courses include formal writing assignments that involve primary or secondary research and, based on review of syllabi and the interviews, assignment lengths are often within the 10 - to 15-page range required by the university's Council on Liberal Education (CLE).

The lack of informal writing in the majority of classes illustrates a deficient area in the curriculum. It may be beneficial to provide faculty members with examples of how informal writing is used in horticultural science classes at other universities to help them incorporate this type of writing into their classes. Informal writing helps students learn course content by encouraging active thought and synthesis of knowledge (Moore, 1994). Informal writing activities can benefit both the students and the teacher by stimulating discussion during lecture, clarifying key points, and allowing exploration of new ideas in a less threatening way than through formal assignments (Moore, 1994).

Faculty who review drafts as part of the writing process noticed a marked improvement in the quality of writing on assignments, but believe that it takes more time than they often have to give to do a quality review. Research has shown, however, that students can catch the majority of their own errors if only representative errors are marked on a draft, reducing the amount of time required by instructors to review a paper (University Writing Program at Virginia Tech, 1998). In addition, too many marks can overwhelm students and shift the focus of revision away from content to surface changes (Dohrer, 1991).

One misconception about the requirement of the critical review process in WI courses revealed in these interviews was the amount of writing that must be reviewed. According to CLE's WI requirements at UMN, one formal writing assignment needs to be reviewed. Because the 10- to 15-page minimum can be met by several assignments rather than one long assignment, faculty can arrange to review drafts of shorter assignments. Separating a formal writing assignment into a series of progressively more complex papers is a more effective way to teach writing and content because it allows students to build their content knowledge and writing skills as the assignments progress (Herrington, 1981). Another benefit is that a critical review of a draft of one of the earlier papers allows for intervention if a concept is not understood, before the assignments become more complex and a larger percentage of the student's grade is at stake (Department of Cultural Studies and Comparative Literature, 1997).

Comments from faculty on their students' ability to write indicated their impression that students come to college as poor writers. This reaffirms the position of UMN that the teaching of writing must be shared across the curriculum in order for students to become proficient writers in their fields (Center for Interdisciplinary Studies of Writing, 2000). The faculty interviewed shared similar views on where WI classes should be placed in the curriculum. The 1000-level classes taken as part of the professional requirements are heavily based on laboratory experience, production techniques, and plant identification. A large amount of hands-on time is spent in these classes to learn the objectives of the course, and the majority of faculty felt that there are many other classes in the curriculum where the WI designation would be a better fit. The consensus was that at least one WI course should be placed in all of the areas of emphasis for the environmental horticulture degree requirements. These are upper-level classes that have fewer students, allowing for more in-depth exploration of topics in horticulture.

Through the interviews, faculty members have been shown that many of their classes are close to meeting
UMN requirements. The environmental horticulture curriculum is giving students many opportunities to learn through writing. Formal writing assigned in the majority of classes allows students to explore their own research or other topics related to the course material in depth. When classes assign informal writing assignments, students learn course material through weekly journals or reflection papers. With minor modifications to the current curriculum to include more informal writing and review of drafts of formal writing assignments, writing can become an even more effective learning tool for undergraduates majoring in environmental horticulture.

\section{Literature cited}

Center for Interdisciplinary Studies of Writing. 2000. Writing at the University: A survival guide for navigating the university's writing requirements. Univ. of Minnesota, Minneapolis.

Department of Cultural Studies and Comparative Literature. 1997. Tips for designing effective assignments. Univ. of Minnesota, Minneapolis.

Dohrer, G. 1991. Do teachers' comments on students' papers help? College Teaching $39(2): 48-54$

Herrington, A.J. 1981. Writing to learn: Writing across the disciplines. College English 43(4): 379-387.

Koprowski, J.L. 1997. Sharpening the craft of scientific writing: A peer-review strategy to improve student writing. J. College Sci. Teaching 27:133-135.

Krest, M. and D.O. Carle. 1999. Teaching scientific writing: A model for integrating research, writing and critical thinking. Amer. Biol. Teacher 61(3):223-227.

Madigan, C. 1987. Writing as a means, not an end. J. College Sci. Teaching $16: 245-250$.

Moore, R. 1994. Writing to learn biology: Let's stop neglecting the tool that works best. J. College Sci. Teaching 23:289-295.

University Writing Program at Virginia Tech. 1998. Evaluation standards: 'Minimal marking' to improve student writing. Info. Flyer Ser. Issue 7. 